\title{
A Replenishment Model of Dual Sales Channels with Lateral Transshipment Problem Considering Consumer Behavior
}

\author{
Dan Huang \\ School of Business Administration, South China University of Technology, Guangzhou, China \\ Email: 18626643726@163.com
}

How to cite this paper: Huang, D. (2017) A Replenishment Model of Dual Sales Channels with Lateral Transshipment Problem Considering Consumer Behavior. iBusiness, 9, 101-110.

https://doi.org/10.4236/ib.2017.94008

Received: November 1, 2017

Accepted: December 9, 2017

Published: December 12, 2017

Copyright $\odot 2016$ by author and Scientific Research Publishing Inc. This work is licensed under the Creative Commons Attribution-NonCommercial International License (CC BY-NC 4.0). http://creativecommons.org/licenses/by/4.0/ (c) (†) Open Access

\begin{abstract}
We study a replenishment model that the retailer shares his leftovers on his direct online sales channel and traditional retail channel. When one of the sales channels is out of stock and another has leftovers, the latter shares its leftovers with the former. Commonly, there is competition between two channels. Therefore, we take the consumers' behavior including retailer inconvenience cost of traditional retail channel, and risks and delivery lead time of direct online sales channel into consideration. Then, we use the function of consumer utility to measure the Demand distribution function. Furthermore, the optimal replenishment models in independent decision-making and in lateral transshipment are established separately. Then the results of two models are compared by order quantity and retailer's profit. What's more, it is found that lateral transshipment between dual sales channel inventory can reduce the order quantity and increase the retailer's profit when the prices and demand distribution satisfy certain conditions. Finally, the numerical analysis of the model is carried out. The validity of the research results is proved by examples.
\end{abstract}

\section{Keywords}

Dual Sales Channels, Consumer Behavior, Lateral Transshipment, Replenishment Model

\section{Introduction}

With the advent of the era of new retailing, e-commerce and traditional retail store increasingly contact. The core of the new retailing is to promote the integration of traditional retail and e-commerce [1]. Compared with "pure e-commerce", retailer needs to prepare more for the new retailing. If the traditional retailers would 
like to get more market share in the fierce competitive market, they have to develop direct online sales channel and traditional retail channel at the same time. However, almost all companies which own dual sales channel would have two apartments to manage dual channels respectively. In that case, it is wasting that retailers need to use more funds and to order more inventories. Therefore, we build a model in which the retailer shares the leftovers on his direct online sales channel and traditional retail channel. When one of the sales channel is out of stock and another has leftovers, the latter shares the leftovers with former.

The research and literatures related to our paper include order model, lateral transshipment and competition between dual sales channel. Firstly, the order model is an important field in supply chain management. In the last hundred years, many scholars have carried out various aspects of the classical model-Economic Order Quantity (EOQ) and Joint Economic-lot Size (JELS) in the inventory model. One of the most important extensions is to consider lateral transshipment of the order model. Lateral transshipment was first proposed by Gross [2], referring to the fact that two companies are at the same level in the supply chain. And one of the companies does not meet all the demands at the end of the quarter, while another has leftovers. Then the latter will share the leftovers with the former. It is not only can improve the former's customer satisfaction, but also can reduce the latter's leftovers. In recent years, the literature on lateral transshipment has become increasingly abundant. On the one hand, many scholars have studied the development of lateral transshipment strategies among enterprises at the same level, for example, Lee [3], Balachander et al. [4] and Tagaras [5] constructed a multi-level inventory model of repairable goods with emergency stocks at a certain level of service; Wee et al. [6] examine the optimal order model when e-commerce retailers share inventory; Chen et al. [7] studied when supplier and retailer both use order-up-to strategy to manage inventory and the customers' demand is random, how they can arrive the overall supply chain's optimal order quantity in lateral transshipment problem. On the other hand, other scholars are committed to a specific situation of lateral transshipment between enterprises. For example, Taesu [8] studied the effect of reallocating stocks on order quantity decisions when retailers transshipped easy-to-corrode goods, and whether it can save funds and other sources on easy-to-corrode goods; Koushik et al. [9] analysis the existence of warehouses and emergency orders between the two kinds of goods and two warehouses in the regular inventory of the order model. Wang Chunxing [10] studied that when the enterprises are in the model of order assembly, lateral transshipment between different modules of enterprises would have impacts of pricing issues. At the same time, they put forward a model to maximize profits of retailers. Among the literatures, the most relevant research with our research is the study of the leftovers shared in dual sales channels [11], but the consumers demand in this article is assumed to be random and independent. However, there is no consideration that consumer behavior and preferences would affect the demand of consumers in duals channels. Therefore, our paper is based on 
Jing's study. But the innovation of our paper is to consider the different service levels between direct online sales channel and traditional retail channel. The service levels would impact customers' decision directly. However, it is difficult to measure the decision of consumers. Bhatnagar, Yan R and XIAO Jian et al. [12] [13] [14] have shown that the inconvenience of traditional retail channel is an important factor for consumers to shopping online, and they define the availability of goods for the traditional retail channel as retailer inconvenience cost. In the direct online sales channels, consumers need to waiting for a long time before they receipt the goods, and they define the waiting time as delivery lead time. Kay-yut chen [15] studied that when retailers sell goods by dual sales channels, consumers' demand mainly depends on service levels of the two channels. However, consumers' valuation of the goods and the shopping experience is key. Yan and Pei [13] divided the decision into centralized decision and decentralized decision, and analyzed the factors that affect the service level of dual sales channels. $\mathrm{Xu}$ [16] classified three different ways to operate online sales channels, including the manufacturer to operate online sales channels, retailer to operate online sales channels and third-party company to operate online sales channels. Han Xiaoya and [17] [18] [19] [20] based on consumer preferences for green goods, retailers' service level the risk of online shopping to build order model and pricing model for retailers.

On the basis of the above scholars, our paper collated in the dual sales channels, the impact of the level of service factors mainly for delivery lead time of online shopping and retailer inconvenience cost of traditional retail channel. Retailer inconvenience cost is the cost of consumers to find and get the goods. Innovations of this paper includes: Firstly, we considered the competitive relationship between the dual sales channels. When the same consumer chooses one of the channels to buy goods, they would like to experience good service. Secondly, to make up for the previous, we studied of independent random demand under the dual sales channel order model, we used function of consumer utility to measuring the dual channel competition under the demand distribution.

\section{Notations}

\section{Assumptions}

Because we use the function of consumer utility to measure the Demand distribution function, we need to assume consumers are rational and risk neutral person. Then, our paper only studies the simple condition that there is a retailer and single kind of goods. What's more, we studied the single-period problem. Therefore, we need to assume that (Table 1):

Hypothesis 1: All consumers are economic rational and risk neutral person.

Hypothesis 2: There is only a retailer and single goods, and all goods are homogeneous.

Hypothesis 3: The retailer can only order the goods one time before the decision period. 
Table 1. Notations and explanations.

\begin{tabular}{cccc}
\hline Notations & Explanations & Notations & Explanations \\
\hline$F(x)$ & $\begin{array}{c}\text { Demand distribution function of } \\
\text { traditional retail channel }\end{array}$ & $p$ & Retail price \\
$f(x)$ & $\begin{array}{c}\text { Density function of traditional retail } \\
\text { channel }\end{array}$ & $\Pi$ & Profit \\
$\mu$ & Demand mean & $q_{1}$ & $\begin{array}{c}\text { Order quantity of traditional } \\
\text { retail channel }\end{array}$ \\
$G(x)$ & $\begin{array}{c}\text { Demand distribution function of } \\
\text { direct online sales channel }\end{array}$ & $q_{2}$ & $\begin{array}{c}\text { Order quantity of direct } \\
\text { online sales channel }\end{array}$ \\
$g(x)$ & $\begin{array}{c}\text { Density function of direct } \\
\text { online sales channel } \\
b\end{array}$ & $U$ & Consumer utility \\
$c$ & Backorder cost & $V$ & Consumers' valuation for goods \\
$W$ & Sales cost & $k$ & Retailer inconvenience cost \\
& Wholesale price & $\Phi$ & Loss aversion function \\
\hline
\end{tabular}

Hypothesis 4: Each consumer can purchase the goods through one of the dual sales channels.

Hypothesis 5: When one of the channels is out of stock, consumers are willing to wait for goods and have no cost of waiting for replenishment.

Hypothesis 6: Residual values and processing costs of leftovers all are zero.

\section{Overall Model}

Learnt from Xu's paper [16], our paper uses consumer utility function to measure consumer demand. In general, the utility function represents a function of the quantitative relationship between the utility of the consumer in terms of consumption and the combination of goods consumed. In this paper, the utility function is used to measure consumers' satisfaction from different channels of consumption. When the consumer's utility is greater than zero, consumers will buy goods through this channel. When the price of dual channels satisfy $p_{1}+k-(1-\phi) \leq p_{2} \leq \phi\left(p_{1}+k\right)$, that is, area II in Figure 1, the consumers will purchase goods by two sales channels. And the demand distribution function of the traditional retail channel and direct online sales channel are as follows:

$$
\begin{gathered}
F\left(p_{1}\right)=1-\frac{p_{1}-p_{2}+k}{1-\phi} \\
G\left(p_{2}\right)=\frac{p_{1}-p_{2}+k}{1-\phi}-\frac{p_{2}}{\phi}
\end{gathered}
$$

According to the article in Zhuang (2011), the traditional retail channel's demand expectations and direct online sales channel's demand expectations are as follows:

$$
\begin{aligned}
E\left(p_{1}\right) & =\int_{0}^{+\infty}\left[1-F\left(p_{1}\right)\right] \mathrm{d} p_{1}-\int_{-\infty}^{0} F\left(p_{1}\right) \mathrm{d} p_{1} \\
E\left(p_{2}\right) & =\int_{0}^{+\infty}\left[1-G\left(p_{2}\right)\right] \mathrm{d} p_{2}-\int_{-\infty}^{0} G\left(p_{2}\right) \mathrm{d} p_{2}
\end{aligned}
$$




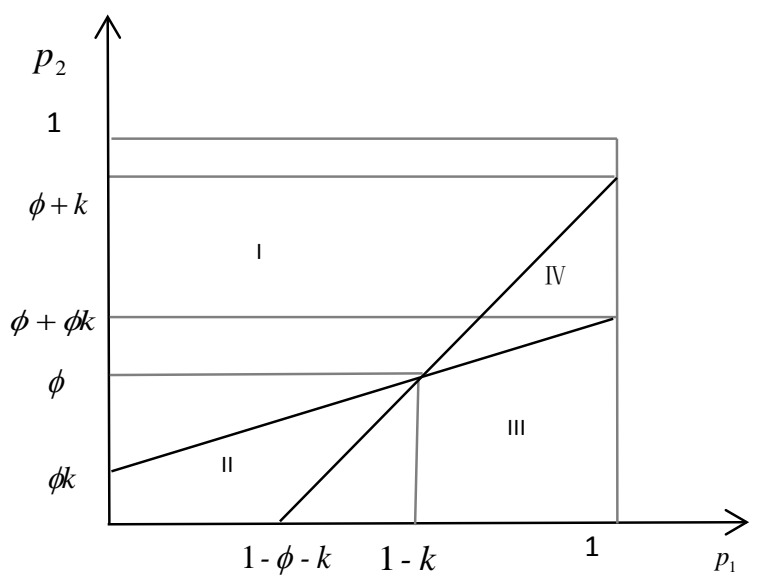

Figure 1. Demand, price and consumers' risk graph.

\subsection{Independent Strategy Model in Dual Sales Channel}

In order to know whether lateral transshipment in dual sales channel is benefit for retailer, we accumulate two cases of optimal order quantity, independent replenishment strategy and replenishment model based on lateral transshipment strategy. First of all, this article establishes an independent order model.

1) The first step is to calculate the optimal order quantity for traditional retail channel of independent replenishment strategy. Obviously, the goal is to maximize the profit of the retailer. It can be seen that the expected sales quantity of traditional retail channel is $\bar{S}_{1}\left(q_{1}\right)=q_{1}-\int_{0}^{q_{1}} F\left(p_{1}\right) \mathrm{d} p_{1}$, expected backorder quantity is $E\left(p_{1}\right)-\bar{S}_{1}\left(q_{1}\right)$, expected profit is $\bar{\Pi}_{1}\left(q_{1}\right)=\left(p_{1}-c_{1}+b_{1}\right) \bar{S}_{1}\left(q_{1}\right)-w q_{1}-b_{1} E\left(p_{1}\right)$.

Because $\bar{\Pi}_{1}\left(q_{1}\right)$ 's second derivative less than zero, we can know:

$$
F\left(\bar{q}_{1}^{*}\right)=\left(\frac{p_{1}-w-c_{1}+b_{1}}{p_{1}-c_{1}+b_{1}}+\frac{p_{2}}{\phi}\right) *(1-\phi)+p_{1}-k
$$

$\bar{q}_{1}^{*}$ is the optimal order quantity for the traditional retail channel of independent replenishment strategy.

2) Similarly, we calculate the optimal order quantity for direct online sales channel of independent replenishment strategy. It can be seen that the expected sales quantity of direct online sales channel is $\bar{S}_{2}\left(q_{2}\right)=q_{2}-\int G(x) \mathrm{d} x$, and expected backorder quantity is $E\left(p_{2}\right)-\bar{S}_{2}\left(q_{2}\right)$, expected profit is $\bar{\Pi}_{2}\left(q_{2}\right)=\left(p_{2}-c_{2}+b_{2}\right) \bar{S}_{2}\left(q_{2}\right)-w q_{2}-b_{2} E\left(p_{2}\right)$.

Because $\bar{\Pi}_{2}\left(q_{2}\right)$ 's second derivative less than zero, we can know:

$$
F\left(\bar{q}_{2}^{*}\right)=p_{1}+k-\frac{w(1-\phi)}{p_{2}-c_{2}+b_{2}}
$$

$\bar{q}_{2}^{*}$ is the optimal order quantity for the direct online sales channel of independent replenishment strategy.

\subsection{Replenishment Model of Lateral Transshipment Strategy in Dual Sales Channel}

When the dual sales channels shared leftovers with each other, there are follow- 
ing conditions:

1) $d_{1}<q_{1}, d_{2}<q_{2}$, both channels' consumer demand can be met, and the two channels have both leftovers. Therefore, we can know:

$$
\begin{aligned}
& E_{11}\left(q_{1}, q_{2}\right)=\int_{0}^{q_{2}}\left[\int_{0}^{q_{1}} p_{1} f\left(p_{1}\right)\right] g\left(p_{2}\right) \mathrm{d} p_{2} \\
& E_{21}\left(q_{1}, q_{2}\right)=\int_{0}^{q_{1}}\left[\int_{0}^{q_{2}} p_{2} f\left(p_{2}\right)\right] f\left(p_{1}\right) \mathrm{d} p_{1}
\end{aligned}
$$

2) $d_{1}>q_{1}, d_{2}>q_{2}$, none of the channels' consumer demand can be met, and the two channels have no leftovers. Therefore, we can know:

$$
\begin{aligned}
& E_{12}\left(q_{1}, q_{2}\right)=\int_{q_{2}}^{+\infty}\left[p_{1}-\left(1-F\left(p_{1}\right)\right)\right] g\left(p_{2}\right) \mathrm{d} p_{2} \\
& E_{22}\left(q_{1}, q_{2}\right)=\int_{q_{1}}^{+\infty}\left[p_{2}-\left(1-G\left(p_{2}\right)\right)\right] f\left(p_{1}\right) \mathrm{d} p_{1}
\end{aligned}
$$

3) $d_{1}<q_{1}, d_{2}>q_{2}$, the direct online sales channel is out of stock, while traditional retail channel has leftovers. We still can classify two following cases:

(1) $d_{1}<q_{1}, q_{2}<d_{2} \leq q_{2}+q_{1}-d_{1}$, the backorder quantity of direct online sales channel is less than leftovers.

(2) $d_{1}<q_{1}, d_{2}>q_{2}+q_{1}-d_{1}$, the backorder quantity of direct online sales channel is more than leftovers. In conclusion, expected sales quantity of traditional retail channel is $E_{13}\left(q_{1}, q_{2}\right)=\int_{q_{2}}^{+\infty}\left[\int_{0}^{q_{1}} p_{1} f\left(p_{1}\right)\right] g\left(d_{2}\right) \mathrm{d} d_{2}$; expected sales quantity of direct online sales channel is

$$
\begin{aligned}
E_{22}\left(q_{1}, q_{2}\right)= & \int_{0}^{q_{1}}\left[\int_{q_{2}+q_{1}-d_{1}}^{+\infty} p_{2} g\left(p_{2}\right) \mathrm{d} p_{2}\right] f\left(p_{1}\right) \mathrm{d} p_{1} \\
& +\int_{0}^{q_{1}}\left[\int_{q_{2}+q_{1}-d_{1}}^{+\infty}\left(q_{2}+q_{1}-d_{1}\right) g\left(p_{2}\right) \mathrm{d} p_{2}\right] f\left(p_{1}\right) \mathrm{d} p_{1}
\end{aligned}
$$

4) $d_{1}>q_{1}, d_{2}<q_{2}$, the traditional retail channel is out of stock, while direct online sales channel has leftovers. We still can classify two following cases:

(1) $d_{2}<q_{1}, q_{1}<d_{1} \leq q_{1}+q_{2}-d_{2}$, the backorder quantity of traditional retail channel is less than leftovers.

(2) $d_{2}<q_{2}, d_{1}>q_{1}+q_{2}-d_{2}$, the backorder quantity is more than leftovers. In conclusion, expected sales quantity of traditional retail channel is

$$
\begin{aligned}
E_{14}\left(q_{1}, q_{2}\right)= & \int_{0}^{q_{2}}\left[\int_{q_{1}}^{q_{2}+q_{1}-d_{2}} p_{1} f\left(p_{1}\right)\right] g\left(p_{2}\right) \mathrm{d} p_{2} \\
& +\int_{0}^{q_{2}}\left[\int_{q_{2}+q_{1}-d_{2}}^{+\infty}\left(q_{2}+q_{1}-d_{2}\right) f\left(p_{1}\right) \mathrm{d} p_{2}\right] g\left(p_{2}\right) \mathrm{d} p_{2}
\end{aligned}
$$

expected sales quantity of direct online sales channel is

$$
E_{24}\left(q_{1}, q_{2}\right)=\int_{q_{1}}^{+\infty}\left[\int_{0}^{q_{2}} p_{2} g\left(p_{2}\right) \mathrm{d} p_{2}\right] f\left(p_{1}\right) \mathrm{d} p_{1}
$$

IN conclusion,

$$
\begin{aligned}
& S_{1}\left(q_{1}, q_{2}\right)=E_{11}\left(q_{1}\right)+E_{12}\left(q_{1}\right)+E_{13}\left(q_{1}\right)+E_{14}\left(q_{1}\right) \\
& S_{2}\left(q_{1}, q_{2}\right)=E_{21}\left(q_{2}\right)+E_{22}\left(q_{2}\right)+E_{23}\left(q_{2}\right)+E_{24}\left(q_{2}\right)
\end{aligned}
$$

The two formulas are calculated and simplified:

$$
S_{1}\left(q_{1}, q_{2}\right)=q_{1}-\int_{0}^{q_{1}} F\left(p_{1}\right) \mathrm{d} p_{1}+\int_{0}^{q_{2}}\left[1-F\left(q_{1}+q_{2}-x\right)\right] G\left(p_{2}\right) \mathrm{d} p_{2}
$$




$$
S_{2}\left(q_{1}, q_{2}\right)=q_{2}-\int_{0}^{q_{2}} G\left(p_{2}\right) \mathrm{d} p_{2}+\int_{0}^{q_{1}}\left[1-G\left(q_{1}+q_{2}-x\right)\right] F\left(p_{1}\right) \mathrm{d} p_{1}
$$

The goal is to maximize the profit of the retailer. It can be seen that the expected sales quantity of traditional retail channel is $S_{1}\left(q_{1}, q_{2}\right)$, expected backorder quantity is $E\left(p_{1}\right)-\bar{S}_{1}\left(q_{1}\right)$, profit function of traditional retail channel is

$$
\bar{\Pi}_{1}\left(q_{1}\right)=\left(p_{1}-c_{1}+b_{1}\right) S_{1}\left(q_{1}, q_{2}\right)-w q_{1}-b_{1} \mu_{1}
$$

$\Pi_{1}\left(q_{1}, q_{2}\right)$ 's first and second order partial guidance are

$$
\begin{aligned}
& \frac{\partial \Pi_{1}\left(q_{1}, q_{2}\right)}{\partial q_{1}}=\left(p_{1}-c_{1}+b_{1}\right)\left(1-F\left(q_{1}\right)-\int_{0}^{q_{2}} f\left(q_{1}+q_{2}-p_{1}\right) G\left(p_{2}\right) \mathrm{d} p_{2}\right)-w \\
& \frac{\partial^{2} \Pi_{1}\left(q_{1}, q_{2}\right)}{\partial q_{1}^{2}}= \\
& \left(p_{1}-c_{1}+b_{1}\right)\left(-f\left(q_{1}\right)\left(1-G\left(q_{2}\right)\right)-\int_{0}^{q_{2}} f\left(q_{1}+q_{2}-p_{1}\right) g\left(p_{2}\right) \mathrm{d} p_{1}\right)<0
\end{aligned}
$$

The profit function $\Pi_{2}\left(q_{1}, q_{2}\right)$ is concave.

Similarly, profit function of direct online sales channel is $\Pi_{2}\left(q_{1}, q_{2}\right)=\left(p_{2}-c_{2}+b_{2}\right) S_{2}\left(q_{1}, q_{2}\right)-w q_{2}-b_{2} \mu_{2}, \Pi_{2}\left(q_{1}, q_{2}\right)$ 's first and second order partial guidance are

$$
\begin{aligned}
& \frac{\partial \Pi_{2}\left(q_{1}, q_{2}\right)}{\partial q_{2}}=\left(p_{2}-c_{2}+b_{2}\right)\left(1-G\left(p_{2}\right)-\int_{0}^{q_{1}} g\left(q_{1}+q_{2}-p_{1}\right) F\left(p_{1}\right) \mathrm{d} p_{1}\right)-w \\
& \frac{\partial^{2} \Pi_{2}\left(q_{1}, q_{2}\right)}{\partial q_{2}^{2}}= \\
& \left(p_{2}-c_{2}+b_{2}\right)\left(-g\left(p_{2}\right)\left(1-F\left(p_{1}\right)\right)-\int_{0}^{q_{1}} f\left(p_{1}\right) g\left(q_{1}+q_{2}-p_{2}\right) \mathrm{d} p_{2}\right)<0
\end{aligned}
$$

The profit function $\Pi_{2}\left(q_{1}, q_{2}\right)$ is concave.

The two sales channels can calculate the optimal order quantities and make decision based on Nash game.

\section{Model Analysis}

\subsection{Comparison Study of Two Strategies}

Compared the above two models, the following theorem can be drawn:

Theorem 1. The equilibrium optimal order quantities need to satisfy the following equals at the same time:

$$
\begin{gathered}
F\left(q_{1}^{*}\right)+\int_{0}^{q_{2}^{*}} f\left(q_{1}^{*}+q_{2}^{*}-x\right) G(x) \mathrm{d} x=\left(\frac{p_{1}-w-c_{1}+b_{1}}{p_{1}-c_{1}+b_{1}}+\frac{p_{2}}{\phi}\right) *(1-\phi)+p_{1}-k \\
G\left(q_{2}^{*}\right)+\int_{0}^{q_{1}^{*}} g\left(q_{1}^{*}+q_{2}^{*}-x\right) F(x) \mathrm{d} x=p_{1}+k-\frac{w(1-\varphi)}{p_{2}-c_{2}+b_{2}}
\end{gathered}
$$

when $q_{1}^{*}$ and $q_{2}^{*}$ to meet the above equals at the same time, both channel arrive their own optimal order quantity.

Theorem 2. $q_{1}^{*}<\bar{q}_{1}^{*}, q_{2}^{*}<\bar{q}_{2}^{*}$, lateral transshipment can reduce order quantity in dual sales channel.

Because 


$$
F\left(q_{1}^{*}\right)+\int_{0}^{q_{2}^{*}} f\left(q_{1}^{*}+q_{2}^{*}-x\right) G(x) \mathrm{d} x=\left(\frac{p_{1}-w-c_{1}+b_{1}}{p_{1}-c_{1}+b_{1}}+\frac{p_{2}}{\phi}\right) *(1-\phi)+p_{1}-k
$$

and $G\left(q_{2}^{*}\right)+\int_{0}^{q_{1}^{*}} g\left(q_{1}^{*}+q_{2}^{*}-x\right) F(x) \mathrm{d} x=p_{1}+k-\frac{w(1-\varphi)}{p_{2}-c_{2}+b_{2}}$, we can kwon $F\left(\bar{q}_{1}^{*}\right)=F\left(q_{1}^{*}\right)+\int_{0}^{q_{2}^{*}} f\left(q_{1}^{*}+q_{2}^{*}-p_{1}\right) G\left(p_{2}\right) \mathrm{d} p_{1}$, and then $\int_{0}^{q_{2}^{*}} f\left(q_{1}^{*}+q_{2}^{*}-p_{1}\right) G\left(p_{1}\right) \mathrm{d} p_{1}>0$, so $F\left(\bar{q}_{1}^{*}\right)>F\left(q_{1}^{*}\right)$. Finally, $F\left(q_{1}^{*}\right)$ is a monotone increasing function, and so $q_{1}^{*}<\bar{q}_{1}^{*}$. similarly, $q_{2}^{*}<\bar{q}_{2}^{*}$.

Theorem 3. when $x \in\left[\min \left(q_{1}^{*}, q_{2}^{*}\right), q_{1}^{*}+q_{2}^{*}\right], 1-F\left(p_{1}\right)-f\left(p_{1}\right)\left(\bar{q}_{1}^{*}-q_{1}^{*}\right) \geq 0$, and $1-G\left(p_{2}\right)-g\left(p_{2}\right)\left(\bar{q}_{2}^{*}-q_{2}^{*}\right) \geq 0$, we can know $\Pi_{1}\left(q_{1}^{*}, q_{2}^{*}\right)>\bar{\Pi}_{1}\left(\bar{q}_{1}^{*}\right)$ and $\Pi_{2}\left(q_{1}^{*}, q_{2}^{*}\right)>\bar{\Pi}_{2}\left(\bar{q}_{2}^{*}\right)$, which means lateral transshipment can improve retailer's profit.

$\Pi_{1}\left(q_{1}^{*}, q_{2}^{*}\right)-\bar{\Pi}_{1}\left(\bar{q}_{1}^{*}\right)=\left(p_{1}-c_{1}+b_{1}\right)(\Phi+\Theta)$, and

$\Phi=\int_{q_{1}^{*}}^{\bar{q}_{1}^{*}}\left(F\left(p_{1}\right)-F\left(q_{1}^{*}\right)\right) \mathrm{d} p_{1}>0$,

$\Theta=\int_{q_{1}^{*}}^{q_{1}^{*}+q_{2}^{*}}\left(1-F\left(p_{1}\right)-f\left(p_{1}\right)\left(\bar{q}_{1}^{*}-q_{1}^{*}\right)\right) G\left(q_{1}^{*}+q_{2}^{*}-p_{1}\right) \mathrm{d} p_{1}$, only when $\Theta \geq 0$, $\Pi_{1}\left(q_{1}^{*}, q_{2}^{*}\right)>\bar{\Pi}_{1}\left(\bar{q}_{1}^{*}\right)$. what's more, when $1-F\left(p_{1}\right)-f\left(p_{2}\right)\left(\bar{q}_{1}^{*}-q_{1}^{*}\right) \geq 0$, $x \in\left[q_{2}^{*}, q_{1}^{*}+q_{2}^{*}\right], \Theta \geq 0$. Inclusion, we can prove the theorem 3 .

\subsection{Numerical Analysis}

To make a numerical analysis of two strategies, we found some data from the Suning online mall and a traditional retailer. However, the original data is not suitable to our conditions above, so we shrink the data at the same rate. And in order to calculate conveniently, we simplify the data at acceptable extent. Then, we assume $p_{1}=0.16, p_{2}=0.16, w=0.1, c_{1}=0.02, c_{2}=0.02, b_{1}=0.02$, $b_{2}=0.02, k=0.4, \phi=0.4$. Then we can calculate the results as followings:

From Table 2, we can learn that lateral transshipment can reduce order quantity and improve retailer's profit at the same time. The optimal order quantity of traditional retail channel is reduced by $24 \%$, and the optimal order quantity of the direct online sales channel is reduced by $13.02 \%$. What's more, the profit of traditional retail channel is increased by $0.1 \%$, and the profit of the direct online sales channel is increased by $14.6 \%$.

\section{Conclusion}

On the basis of Nash equilibrium, our paper built a replenishment order model of lateral transshipment under the dual sales channel. It is concluded that lateral transshipment between traditional retail sales channel and direct online sales channel can reduced the optimal order quantity and improve retailer's profit at the same time when the two channels' price meets certain conditions. We can learn some management revelations of dual sales channels' inventory strategy. First of all, we took impacts of consumer behavior on consumer demand into consideration, and we use function of consumer utility to measure the dual sales channel's demand function when dual sales channels are competitive. Then it's compared that 
Table 2. Numerical analysis of independent replenishment strategy and lateral transshipment strategy.

\begin{tabular}{cccccc}
\hline \multicolumn{6}{c}{ Independent decision-making strategy } \\
\hline $\bar{q}_{1}^{*}$ & $\bar{q}_{2}^{*}$ & $\bar{S}_{1}^{*}\left(q_{1}, q_{2}\right)$ & $\bar{S}_{2}^{*}\left(q_{1}, q_{2}\right)$ & $\bar{\Pi}_{1}^{*}$ & $\bar{\Pi}_{2}^{*}$ \\
0.7 & 0.225 & 0.333 & 0.27 & 0.0456 & 0.020444 \\
\hline \multicolumn{5}{c}{ Lateral transshipment strategy } \\
\hline$q_{1}^{*}$ & $q_{2}^{*}$ & $S_{1}^{*}\left(q_{1}, q_{2}\right)$ & $S_{2}^{*}\left(q_{1}, q_{2}\right)$ & $\Pi_{1}^{*}\left(q_{1}, q_{2}\right)$ & $\Pi_{2}^{*}\left(q_{1}, q_{2}\right)$ \\
0.532 & 0.1957 & 0.3302 & 0.2481 & 0.04564 & 0.02344 \\
\hline
\end{tabular}

the two sales channels' decentralized order model and lateral transshipment strategy model. Furthermore, by comparing the optimal order quantity and the maximum profit of the retailer in both cases, we can learn from the results that lateral transshipment would result in an increase in profit and a decrease in order quantity. Thereby it can reduce inventory holding costs and the risk of inventory waste. Finally, the numerical analysis is used to prove the authenticity and accuracy of the order model of this paper. Innovations of this paper include that we consider the competitive relationship between the dual sales channels. When the same consumers choose one of the channels to buy goods, they would like to experience good service. What's more, to make up for the previous study of independent random demand under the dual sales channel order model, we use function of consumer utility to measure the dual channel competition under the demand distribution. However, this paper still exist a lot of limitations, such as only studying single-period, single product problem, but did not take the consumer's waiting cost, reverse logistics costs into account. In the future study, we will improve this paper by extending the above conditions, so that the study results closer to the reality.

\section{References}

[1] Du R.-Y. and Jiang, K. (2017) New Retailing: Connotation, Development Impetus and Key Problems. Price: Theory \& Practice, No. 2, 139-142.

[2] Gross, D. (1963) Centralized Inventory Control in Multipli-Cation Supply Systems. In: Scarf, H.E., Gilford, D.M. and Shelly, M., Eds., Multistage Inventory Models and Techniques, Stanford University Press, Redwood City.

[3] Lee, H.L. (1987) A Multi-Echelon Inventory Model for Repairable Items with Emergency Lateral Transshipments. Management Science, 33, 1302-1316. https://doi.org/10.1287/mnsc.33.10.1302

[4] Balachander, S. and Farquhar, P.H. (1994) Gaining More by Stocking Less: A Competitive Analysis of Product Availability. Marketing Science, 13, 3-22. https://doi.org/10.1287/mksc.13.1.3

[5] Tagaras, G. (1989) Effects of Pooling on Optimization and Service Levels of Two-Location Inventory Systems. IIE Transactions, 21, 250-257. https://doi.org/10.1080/07408178908966229

[6] Wee, K.F. and Dada, M. (2007) Optimal Policies for Transshipping Inventory in a Retail Network. Management Science, 51, 1519-1533. https://doi.org/10.1287/mnsc.1050.0441 
[7] Chen, Y.J. (2010) Optimal Selling Scheme for Heterogeneous Consumers with Uncertain Valuations. Mathematics of Operations Research, 36, 695-720. https://doi.org/10.1287/moor.1110.0514

[8] Taesu, C. (2013) Joint Inventory and Transshipment Control for Perishable Products of a Two-Period Lifetime. International Journal of Advanced Manufacturing Technology, 66, 1327-1341. https://doi.org/10.1007/s00170-012-4411-x

[9] Koushik, S., Moosa, R., Yun, S. and Lim, F. (2015) A Two-Item Two-Warehouse Periodic Review Inventory Model with Transshipment. Annals of Operations Research, 233, 365-381. https://doi.org/10.1007/s10479-013-1483-4

[10] Wang, C.-X. and Dong, M. (2009) Product Line Selection and Pricing Problem Under Assemble-to-Order and Inventory Pooling Strategy. Industrial Engineering and Management, 14, 42-48.

[11] Jing, Y.-G., Zhang, A.-F. and Qin, K.-D. (2016) Joint Replenishment Model of Double Channels with Sharing Leftovers under Independent and Stochastic Demand. Systems Engineering, 34, 67-72.

[12] Bhatnagar, A., Misra, S. and Rao, H.R. (2000) On Risk, Convenience, and Internet Shopping Behavior. Communications of the ACM, 43, 98-105.

https://doi.org/10.1145/353360.353371

[13] Yan, R. and Pei, Z. (2009) Retail Services and Firm Profit in a Dual-Channel Market. Journal of Retailing and Consumer Services, 16, 306-314. https://doi.org/10.1016/j.jretconser.2009.02.006

[14] Xiao, J., Dan, B. and Zhuang, X.-M. (2010) Service Cooperation Pricing Strategy between Manufacturers and Retailers in Dual-Channel Supply Chain. Systems Engineering-Theory \& Practice, 30, 2203-2211.

[15] Chen, K., Kaya, M. and Ozer, O. (2008) Dual Sales Channel Management with Service Competition. Manufacturing \& Service Operations Management, 10, 654-675. https://doi.org/10.1287/msom.1070.0177

[16] Xu, L. and Li, Y. (2013) On Supply Chain Mixed Channel Problem Considering Consumer Behavior. Systems Engineering-Theory \& Practice, 33, 1673-1680.

[17] Han, X. (2017) Optimal Production and Ordering Decisions Considering Different Consumers' Behaviors. PhD University of Science and Technology of China, Hefei.

[18] Guo, Y. and Zhao, L. (2008) The Conflict and Coordination in Dual Channel Based on E-Market. Systems Engineering-Theory \& Practice, 28, 59-66.

[19] Hanany, E., Tzur, M. and Levran, A. (2010) The Transshipment Fund Mechanism; Coordinating the Decentralized Multiplication Transshipment Problem. Naval Research Logistics, 57, 315-353.

[20] Friberg, R., Ganslandt, M. and Sandstrom, M. (2001) Pricing Strategies in E-Commerce: Bircks vs. Clicks. Working Paper, Stockholm School of Economies, Sweden. 